\title{
Capacity Sizing of a Small Hydropower Plant using Assured Energy Analysis
}

\author{
J.H.I. Ferreira ${ }^{1}$, J.R. Camacho ${ }^{2}$ \\ ${ }^{1}$ Instituto Federal do Triângulo Mineiro - Câmpus Ituiutaba \\ Rua Belarmino Vilela Junqueira s.n ${ }^{\circ}$, Bairro Novo Tempo 2, CEP:38.305-200, Ituiutaba-MG \\ Phone:+55 34992096189 e-mail: jacson@iftm.edu.br \\ ${ }^{2}$ School of Electrical Engineering, Universidade Federal de Uberlândia \\ Av.: João Naves de Ávila, nº 2121, Bairro: Santa Mônica, CEP: 38.408-100, Uberlândia-MG, Brazil \\ Phone:+55 3432394734 e-mail: jrcamacho@ufu.br
}

\begin{abstract}
For a Small Hydropower Plant (SHP), the installation capacity is one of the most important issues in planning step. This paper presents a methodology for the capacity sizing of SHP based on assured energy. The analyzes were substantiated on historical series with daily streamflow data, operating limits of the turbines, forced unavailability due to the minimum streamflow of the turbine, Turbine efficiency variation in function of the streamflow variation and a project with two turbines operating in parallel of different type and size. The methodology was developed at the Tijuco River Basin in Brazil, with the data of Ituiutaba fluviometric station. It was used the time series from 1975 to 2017 (43 years). The results show that the analysis can be executed already in the initial phases of a hydroelectric project of the SHP.
\end{abstract}

\section{Key words}

Small Hydropower Plant, Assured Energy, Renewable Energy, Turbine Efficiency, Hydroelectric Potential Estimate.

\section{Introduction}

In the initial stages of implementation of a Small Hydropower Plant (SHP) project is important and necessary to execute studies to estimate and to plan the viability and reliability of the hydroelectric potential, in order to identify the optimum use of SHP in the hydraulic, economic and environmental aspects [1]. The characteristics associated with energy production are estimated in the basic project, serving as a guide for the determination of the assured energy.

Within the Brazilian electrical system, there is the concept of assured energy for small hydropower plants. This concept is based on the uncertainty of generation by these plants, resulting from hydrological factors and from interruptions of the generator set, programmed or involuntary. Thus, determining assured energy of the SHP reflects its generation share in the system which it belongs $[2]$.

The resolution 673/2015 of ANEEL (National Agency of Electric Energy) [3] establishes the requirements and procedures to obtain authorization of uses with characteristics of SHP. According the resolution, the assured energy is one of the requirements for the SHP project, as well the parameters used for its calculation.

The assured energy term presents a different definition in practice according each of the agents of the electric sector. For regulatory agencies, the assured energy represents the amount of energy that the power plant can supply to the national interconnected system with a level of reliability. For energy generation agents, the assured energy is the amount of energy sales, i.e., how much can be traded in energy sales contracts [4].

SHPs are classified as hydropower plants dispatched in a non-centralized way by the National System Operator (ONS) because they do not demand a coordination by ONS. According Technical Note 63/2012 [5], it has been verified in some SHPs that, during operation, the energy production is smaller than the calculated during the project. Among the problems caused by the difference between project and operation are not sufficient energy to meet the demand, lack of energy security and remuneration of agents for an energy not effectively delivered.

A highlight and important point for calculating the assured energy of a SHP is the streamflow time series. The Ordinance 463/2009 of Brazilian Ministry of Mines and Energy (MME) [6], which establishes the calculation and revision of the amounts of assured energy, establishes that the historical series must have the average monthly streamflow (in $\mathrm{m}^{3} / \mathrm{s}$ ) and not be less than thirty years, generated in a way that is as extensive and updated as 
possible. But, some authors presented studies showing the importance of using the historical series based on daily average streamflow [2] [4]. They considered that the calculation with monthly data overestimate generation capacity of SHP in $30 \%$.

Therefore, this research contributed, through the methodology specified by the MME ordinance, in the evaluation of the hydroelectric potential of new projects and calculation of the installed capacity of the SHP. Based on previous researches, the methodology applied in this paper comprehended the following aspects:

- Time series of average daily streamflow;

- Operating limit based on turbine utilization limits;

- Forced unavailability due to the minimum streamflow of the turbine;

- Turbine efficiency variation in function of the streamflow variation;

- Two turbines operating in parallel that differ in size and even in type.

\section{Capacity Sizing of a SHP}

\section{A. Assured Energy}

To evaluate the assured energy of the hydropower plants that have not entered in commercial operation until definition date of this value, the MME ordinance determines the calculation of the assured energy for SHP in accordance with Eq. (1).

$$
\begin{aligned}
& G F e=\left[\sum_{i=1}^{n}\left(Q_{i}-\left(q_{r}+q_{\mu}\right) * 9,81 *(H b-h) * \eta_{t g}\right] *\right. \\
& (1-P e r) *(1-T E I F) *(1-I P) * \frac{1}{n * 1000}-C_{I N T}
\end{aligned}
$$

where, $n=$ number of the months of time series; $Q i=$ average monthly streamflow $\left(\mathrm{m}^{3} / \mathrm{s}\right) ; q_{r}=$ remaining streamflow $\left(\mathrm{m}^{3} / \mathrm{s}\right) ; q_{u}=$ consumptive streamflow $\left(\mathrm{m}^{3} / \mathrm{s}\right)$; $H b=$ gross height $(\mathrm{m}) ; h=$ hydraulic losses $(\mathrm{m}) ; \eta_{t g}=$ turbine-generator efficiency; Per = electric losses (MW); $T E I F=$ forced unavailability $(\%) ; I P=$ scheduled unavailability (\%); $C_{I N T}=$ intern consumption (MW); GFe = assured energy (MWmed);

Some technical information on the MME formula was discussed and regulated during ANEEL Public Hearings No. $63 / 2012$ and $68 / 2013$, in order to bring the generation closer to the real ones. As the generation demonstrates that the values implanted are higher than those considered in the project, the interested party may request revision of the assured energy.

Table I summarizes the values proposed during the hearings to be used in the execution of the basic projects of a SHP. The 68/2013 hearing was the one that defined the regulatory parameters associated with the approval of basic projects of plants not centrally dispatched.
Table I. Regulatory parameters to SHP basic projects

\begin{tabular}{ccc} 
& $\begin{array}{c}\text { Audience } \\
\text { 63/2012 [5] }\end{array}$ & $\begin{array}{c}\text { Audience } \\
\mathbf{6 8 / 2 0 1 3}[7]\end{array}$ \\
\hline Parameters & Valor & Valor \\
\hline Turbine Efficiency & $87.5 \%$ & $91 \%$ \\
Generator Efficiency & $1.26 \%$ & $97 \%$ \\
TEIF & $4.45 \%$ & $3.26 \%$ \\
IP & $2 \%$ & $2 \%$ \\
h (compact type) & $3 \%$ & $3 \%$ \\
h(derivation type) & $1.55 \%$ & Equation \\
Per & $1 \%$ & $0.30 \%$ \\
$\boldsymbol{C}_{\boldsymbol{I N T}}$ & &
\end{tabular}

According Table I, the turbine-generator efficiency changed (87.5\% to $88.3 \%), I P$ and $C_{I N T}$ decreased and $P e r$ is computed from line characteristics (voltage and length of line and conductor resistance) and the power generated (calculated from monthly streamflow time series).

Since the methodology proposed in this research sought to evaluate the generation according to the operational limits of the turbines and the variation of the efficiency as a function of the flow variation, all the variables of Equation 1 were equal to the values established by the Public Hearing 68/2013, except: the nominal turbine efficiency - determined by turbine efficiency curves; TEIF - determined by the number of times the turbine has ceased to work due to its operational limit and minimum ecological flows; and for Losses (Per) was used the value of the Public Hearing 63/2012,- since the determination of the line characteristics was not the object of study in this research.

\section{B. Turbine Efficiency and TEIF}

The hydraulic efficiency represents the real utilization of the potential energy available in the system. It depends of turbine type, the river available streamflow (turbinated streamflow- $Q_{T}$ ) and turbine nominal streamflow (project streamflow- $Q_{P}$ ). Each turbine has an efficiency curve characterized for a maximum value of nominal streamflow and an operating range. Figure 1 shows the efficiency curves of two standard turbines.

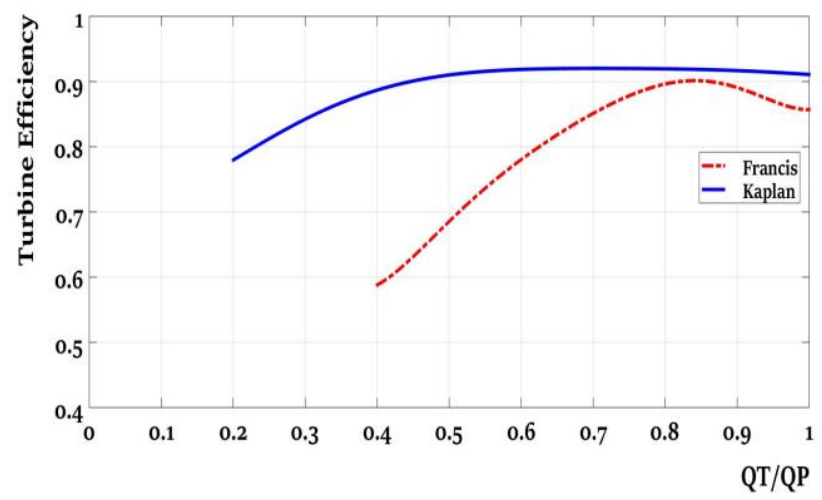

Fig. 1. Efficiency curves of Kaplan and Francis turbines. Source: SEMI Industrial [8] 
The operating range of a selected type is introduced according to the specifications of the turbine's manufacturers. The turbine can operate when the streamflow is between a minimum and maximum streamflow value [9]. The lower limit is about $40 \%$ of the nominal streamflow for Francis turbines and $25 \%$ for Kaplan turbines [10].

These operating limits were used to determine the minimum streamflow of the turbines, it is necessary to present their values as stated in the MME ordinance. However, in addition to specifying the minimum streamflow, the operating limits were used for the determination of TEIF. The value of TEIF was determined by the number of times the turbines reached their operating limit divided by the number of data at time series in the study.

\section{Alternatives and Proportionality}

In order to evaluate the generation of energy through turbines in parallel operation, this research proposed an estimation of the assured energy using two turbines that may be different in type and size. The numerical study evaluated 20 alternatives created with two turbines. The size of the turbines was based on the project streamflow proportionality. Example: $Q_{P 1}=0.9 Q_{P}$ e $Q_{P 2}=0.1 Q_{P}$. Table II shows the alternatives.

Table II. Alternatives and project streamflow proportionality with turbine type

\begin{tabular}{|c|c|c|}
\hline & Turbine 1 & Turbine 2 \\
\hline SHP 1 & 0.9 Francis & 0.1 Francis \\
\hline SHP 2 & 0.9 Francis & 0.1 Kaplan \\
\hline SHP 3 & 0.9 Kaplan & 0.1 Francis \\
\hline SHP 4 & 0.9 Kaplan & 0.1 Kaplan \\
\hline SHP 5 & 0.8 Francis & 0.2 Francis \\
\hline SHP 6 & 0.8 Francis & 0.2 Kaplan \\
\hline SHP 7 & 0.8 Kaplan & 0.2 Francis \\
\hline SHP 8 & 0.8 Kaplan & 0.2 Kaplan \\
\hline SHP 9 & 0.7 Francis & 0.3 Francis \\
\hline SHP 10 & 0.7 Francis & 0.3 Kaplan \\
\hline SHP 11 & 0.7 Kaplan & 0.3 Francis \\
\hline SHP 12 & 0.7 Kaplan & 0.3 Kaplan \\
\hline SHP 13 & 0.6 Francis & 0.4 Francis \\
\hline SHP 14 & 0.6 Francis & 0.4 Kaplan \\
\hline SHP 15 & 0.6 Kaplan & 0.4 Francis \\
\hline SHP 16 & 0.6 Kaplan & 0.4 Kaplan \\
\hline SHP 17 & 0.5 Francis & 0.5 Francis \\
\hline SHP 18 & 0.5 Francis & 0.5 Kaplan \\
\hline SHP 19 & 0.5 Kaplan & 0.5 Francis \\
\hline SHP 20 & 0.5 Kaplan & 0.5 Kaplan \\
\hline
\end{tabular}

\section{Installed Capacity}

From the concept of assured energy, already presented where its value portrays the generation capacity of the plant, the installed power was determined. According to ELETROBRAS's Basic Projects Handbook in Brazil [11], the installed power of a SHP can be calculated through Eq. (2).

$$
P=\frac{E}{F C \cdot \Delta t}
$$

where, $P$ is installed power (MW); $E$ is energy (MWh); $F C$ is capacity factor (adopted 0.55 ); and $\Delta t$ is the time interval $(\mathrm{h})$.

With the assured energy and an evaluation of annual generation, it is possible to determine the annual produced energy by Eq. (3)

$$
E=G F e * \Delta t
$$

where, $E$ is assured energy (MWh); e $G F e$ is assured energy of the plant (MWmed).

Substituting Eq. (3) in Eq. (2), it is possible to calculate the installed capacity of the SHP through assured energy by Eq. (4).

$$
P=\frac{G F e}{F C}
$$

\section{Case Study}

\section{A. Site of study}

The time series data with average daily streamflow was obtained by Ituiutaba fluviometric station, located in Tijuco River, Ituiutaba, Minas Gerais state, Brazil. Data were available by the National System of Information on Water Resources (SNIRH) through the HidroWeb platform, managed and coordinated by the National Agency of Water - ANA [12].

The Ituiutaba station has data records from 1942 to 2017. However, there are many faults in the observations or no information in the time series since its beginning (problem caused by failure of the recording equipment and/or with the operator of the station). Thus, it was used the time series from 1975 to 2017 (43 years). This period has a lower number of registry failures. In total, the time series has 14,964 records of daily streamflow, representing $95.34 \%$ of the data for 1975 to 2017 period. Table III shows some important statistic data about the time series.

Table III. Statistic data of the time series from 1975 to 2017

\begin{tabular}{cccc}
\hline $\boldsymbol{Q}_{\text {MAX }}\left(\mathrm{m}^{3} / \mathrm{s}\right)$ & 811.92 & $\boldsymbol{Q}_{95 \%}\left(\mathrm{~m}^{3} / \mathrm{s}\right)$ & 30.84 \\
$\boldsymbol{Q}_{\text {MIN }}\left(\mathrm{m}^{3} / \mathrm{s}\right)$ & 3.23 & $\mathbf{Q}_{98 \%}\left(\mathrm{~m}^{3} / \mathrm{s}\right)$ & 24.05 \\
$\boldsymbol{Q}_{M E D}\left(\mathrm{~m}^{3} / \mathrm{s}\right)$ & 97.90 & $\boldsymbol{Q}_{7,10}\left(\mathrm{~m}^{3} / \mathrm{s}\right)$ & 15.14 \\
S.D. $\left(\mathrm{m}^{3} / \mathrm{s}\right)$ & 47.02 & & \\
\hline
\end{tabular}

According Brazilian legislation [11], the streamflow with probability of occurrence in $95 \%$ of time $\left(Q_{95 \%}\right)$ can be used as a reference for SHP projects. Thus, the streamflow project $\left(Q_{P}\right)$ for the local was $30 \mathrm{~m}^{3} / \mathrm{s}$.

In the State of Minas Gerais, the reference streamflow to be used for the calculation of the water availability in each landmark is $Q_{7,10}$ streamflow. The $Q_{7,10}$ streamflow is the average annual minimum streamflow of 7 days $\left(Q_{7}\right)$ with a 
return period of 10 years. It is necessary to ensure the downstream of each derivation a minimum residual streamflow of $70 \%$ of the $Q_{7,10}[13]$.

For this study, the Weibull distribution function was applied because it is regarded as one of the most common distribution parameters used in calculating minimum river streamflow [14]. Thus, the residual streamflow $\left(Q_{R E S}\right)$ established for the local, who is the value is the sum of the remaining streamflow $\left(q_{r}\right)$ with consumptive streamflow $\left(q_{u}\right)$, was $10.6 \mathrm{~m}^{3} / \mathrm{s}$.

Doing a preliminary analysis with the time series data available. In 48 records the river streamflow was lower than residual streamflow. This condition prevents the operation of the SHP. There are some researches of hybrid implementation trough the utilization of residual streamflow of the plant. It is created a specific generator set to produce energy with the residual streamflow. For this paper, the residual streamflow was considered as a minimum streamflow for the operation of the SHP, i.e., when the records were lower than residual streamflow, it was counted as plant forced unavailability.

Still on the preliminary analysis of the time series, in 12,421 records the river streamflow was greater than the project streamflow $\left(30 \mathrm{~m}^{3} / \mathrm{s}\right)$, representing $83 \%$ of the records. For this analysis, the value of residual streamflow was deducted of the value of river streamflow. It shows that in $83 \%$ of the time the two turbines worked with their nominal values. To calculate the produced power by the turbines, the project streamflow for these records was divided in accordance with the proportionalities presented in Table III. For example, if the turbines 1 and 2 have $60 \%$ and $40 \%$ of the project streamflow, respectively, so the turbinated streamflow $Q_{T 1}$ e $Q_{T 2}$ are $18 \mathrm{~m}^{3} / \mathrm{s}$ and 12 $\mathrm{m}^{3} / \mathrm{s}$, respectively.

For the rest of records, the river streamflow was lower than the project streamflow (16.67\%). In these cases, the produced powers by the turbines were calculated using the river streamflow and dividing its value in accordance with the project proportionality. For example, if the river streamflow is $24 \mathrm{~m}^{3} / \mathrm{s}$ and the turbines 1 and 2 have $60 \%$ and $40 \%$ of project streamflow, respectively, so the turbinated streamflow $Q_{T 1}$ e $Q_{T 2}$ are $14.4 \mathrm{~m}^{3} / \mathrm{s}$ and 9.6 $\mathrm{m}^{3} / \mathrm{s}$, respectively.

However, there is another relevant aspect when the records are smaller than the project streamflow: the operating limits of the turbines. The ratio between turbinated streamflow and project streamflow is the value that determines the operating limit of the turbines. For Francis turbines is 0.25 and for Kaplan turbine is 0.40 . It shows that Kaplan turbine have a longer operating rate than the Francis turbine, operating in more diverse situations when there are variations in the streamflow. This way, in the division of proportionality, there were cases that turbines did not work due to their operating limits. When it happened, the forced unavailability increased.

\section{B. Results and Discussions}

To calculate the assured energy was considered $H b$ equal $10 \mathrm{~m}$ and derivation type $(h=3 \%)$. Table IV as follows shows the results to TEIF, average turbine efficiency, assured energy and installed power for each alternative created.

Table IV. Results of TEIF, $\eta, G F e$ and $P$ for all alternatives

\begin{tabular}{cccccc} 
& $\begin{array}{c}\text { TEIF } \\
(\%)\end{array}$ & $\begin{array}{c}\boldsymbol{\eta}_{1} \\
(\%)\end{array}$ & $\begin{array}{c}\boldsymbol{\eta}_{2} \\
(\%)\end{array}$ & $\begin{array}{c}\text { GFe } \\
(\text { MWmed })\end{array}$ & $\begin{array}{c}\boldsymbol{P} \\
(\boldsymbol{M W})\end{array}$ \\
\hline SHP 1 & 2.71 & 87.4 & 87.4 & 2.166 & 3.94 \\
SHP 2 & 1.26 & 87.4 & 91.0 & 2.207 & 4.01 \\
SHP 3 & 1.26 & 91.0 & 87.4 & 2.282 & 4.15 \\
SHP 4 & 1.26 & 91.00 & 91.0 & 2.292 & 4.17 \\
SHP 5 & 2.71 & 87.4 & 87.4 & 2.166 & 3.94 \\
SHP 6 & 1.26 & 85.7 & 88.8 & 2.216 & 4.03 \\
SHP 7 & 1.26 & 91.0 & 87.4 & 2.272 & 4.13 \\
SHP 8 & 1.26 & 91.0 & 91.0 & 2.292 & 4.17 \\
SHP 9 & 2.71 & 87.4 & 87.4 & 2.166 & 3.94 \\
SHP 10 & 1.26 & 87.4 & 91.0 & 2.225 & 4.05 \\
SHP 11 & 1.26 & 91.0 & 87.4 & 2.263 & 4.11 \\
SHP 12 & 1.26 & 91.0 & 91.0 & 2.292 & 4.17 \\
SHP 13 & 2.71 & 87.4 & 87.4 & 2.166 & 3.94 \\
SHP 14 & 1.26 & 87.4 & 91.0 & 2.235 & 4.06 \\
SHP 15 & 1.26 & 91.0 & 87.4 & 2.254 & 4.10 \\
SHP 16 & 1.26 & 91.0 & 91.0 & 2.292 & 4.17 \\
SHP 17 & 2.71 & 87.4 & 87.4 & 2.166 & 3.94 \\
SHP 18 & 1.26 & 87.4 & 91.0 & 2.245 & 4.08 \\
SHP 19 & 1.26 & 91.0 & 87.4 & 2.245 & 4.08 \\
SHP 20 & 1.26 & 91.0 & 91.0 & 2.292 & 4.17 \\
\hline
\end{tabular}

With Table IV, it is possible to consider the following arguments:

a) SHP alternatives $1,5,9,13$ and 17 have the same technical values, as well as SHP alternatives 4, 8, 12, 16 e 20. For each set of alternatives mentioned, the same turbine type and different sizes were used. The use of different sizes and same type does not change the production of SHP.

b) The forced unavailability rate (TEIF) was lower when the alternative had at least one Kaplan turbine. In 15 of the 20 alternatives created for the study case, the SHP project would be in accordance with the TEIF value established in Public Audience 68/2013 (Table I).

c) Observing the values of the average efficiency of alternatives, with Kaplan turbine was possible to obtain $91 \%$, a value equal to the established at Audience 68/2013 for the efficiency of the turbine. With the use of Francis turbine, the obtained value was $87.43 \%$. It happened because there is a difference among the turbine curves (Figure 1). Kaplan turbine have an efficiency equal to $91 \%$ for a streamflow variation rate between 0.6 and 1 . Francis turbine have this value for the efficiency when the streamflow variation rate is between 0.8 and 0.9 .

d) The best result of assured energy is $2.292 \mathrm{MWmed}$ and it is possible to find this value in five alternatives $(4,8,12$, 16 e 20). These alternatives have Kaplan type for the both turbines, with the same and different sizes. The 
alternatives 3 and 7 have a value close of assured energy to the alternatives with the best results. They differ in type and size, but the Kaplan turbine has the highest proportional project.

For all these aspects discussed about the records of streamflow, the methodology for capacity sizing of a SHP through the concept of assured energy and the perspective of two turbines operating in parallel of different types and sizes is relevant due to the relation between evaluating the power generation and the lower forced unavailability rate. All this analysis can be executed already in the initial phases of a hydroelectric project of the SHP.

\section{Conclusion}

The Brazilian hydrography is responsible for $60 \%$ of electric energy production. As a result, the energy matrix of the country depends on the hydraulic system and in periods of drought needs to resort to other sources to meet the demand for energy consumption.

For increase the relevance and potential of SHP in the Brazilian electrical system is necessary that the operation of the plants achieve high levels of reliability during all the days of the year, especially in drought periods. Also, to maximize the energy production at the plant installation site. Thus, the SHP projects need to have good efficiency and reliability.

The proposed methodology and the results presented in this research demonstrates that, in the initial phase of SHP projects, it is feasible and important to evaluate the hydroelectric potential of new plants, highlighting and paying attention to the results of possible alternatives.

The methodology is also presented as a good model under energy and efficiency point of view, since the capacity size of SHP is directly related to the historical record of the plant deployment site. The value of the installed power using the assured energy allows the plant to produce energy according to the variations of the river flow, without the risk of incurring in a plant under or oversizing.

However, the technical evaluation of the alternatives associated with the economic issues of the project, such as investment and sales of energy, would allow a greater weighting on the project aspects during the implementation phase. Therefore, it considers as recommendation for future research the combination of economic and technical evaluation.

\section{Acknowledgement}

The authors thanks SEMI Industrial for providing technical data for the development of this research. Thanks also to IFTM and UFU for making available researchers and physical space, and to CAPES, CNPq and FAPEMIG for the financial support.

\section{References}

[1] C. S. M. Júnior, I. C. Nasser, M. M. Filho, O. L. Tortelli. "Estimating the physical guarantee of hydroelectric plants with non-centralized dispatch". Brazilian Journal of Energy, 2016, v.22, n.2, p.44-53. \{In portuguese\}

[2] B. T. C. Vasconcellos. "Analysis of the physical guarantee of hydroelectric plants not centrally dispatched and the potential of hybrid complementation. MSc Dissertation, Universidade Federal de Itajubá, Itajubá, Minas Gerais, Brazil, 2018. \{In portuguese\}

[3] ANEEL - National Electrical Energy Agency. Resolution no 673, August 4, 2015. Establishes the criteria for the framework of hydroelectric use in the condition of Small Hydroelectric Power Plant. Official Diary of the Union, Brasília, FD, August 31, 2015, Section 1; p.118. \{In portuguese\}

[4] M. L. B. Silva. "Analysis of the methodology of the MME / ANEEL for the calculation of the amounts of assured energy and energy physical guarantee of SHPs: Case study of a SHP." End of course work, Universidade Federal de Santa Catarina, Florianópolis, Santa Catarina, Brazil, 2016. \{In portuguese\}

[5] ANEEL - National Electrical Energy Agency. Technical Note $\mathrm{n}-63$, August 29, 2012. Definition of regulatory parameters associated with the approval of basic projects of hydroelectric plants not centrally dispatched. IIn portuguese?

[6] MME - Ministério de Minas e Energia. Ordinance no -463 , December 3, 2009. Establishes the methodology for calculating and reviewing the amounts of energy physical guarantee of Hydroelectric Power Plants not centrally dispatched by the National Electric System Operator - ONS. Official Diary of the Union, Brasília, DF, December 4, 2009, Section 1, p.74. \{In portuguese\}

[7] ANEEL - National Electrical Energy Agency. Technical Note $\mathrm{n}-68$, September 6, 2013. Analysis of contributions in AP 068/2012, referring to the definition of regulatory parameters associated to the approval of basic projects of not centrally dispatched hydroelectric plants. \{In portuguese?

[8] SEMI Industrial. SHP - Small Hydro Plant. Available at: http://www.semi.com.br \{In portuguese\}

[9] Anagnostopoulos JS, Papantonis DE. Optimal sizing of a run-of-river small hydropower plant. Energy Conversion \& Management 2007; 48:2663-2670. https://doi.org/10.1016/j.enconman.2007.04.016.

[10] Barrero JMB, Muro JCSD, Macías EJ, de la Parte MP. Comparasion in the aplication of the exploitation by optimal head model to hydroelectric power station in runof-river systems with different types of turbines. Renewable Energy \& Power Quality Journal 2011; 9:1338-1343. https://doi.org/10.24084/repqj09.643.

[11] Brazilian Power Plants. Guidelines for studies and smallscale projects Hydraulics. Rio de Janeiro, Brazil, 2000. 458 p. \{In portuguese $\}$.

[12] National Water Agency. National information system on water resources. Availabe from: <http://www.snirh.gov.br. \{In portuguese\}

[13] MINAS GERAIS INSTITUTE OF WATER MANAGEMENT. Ordinance $\mathrm{n}^{\circ} 49$, de July 012010 . Establishes the procedures for the regularization of the use of water resources in the state of Minas Gerais, Executive Power Journal, Belo Horizonte, MG, Brazil, July 06,. 2010. \{In portuguese\}.

[14] A. A. Reis, M. Naghettini and M. D. Melo, "Comparative Study, Application and Setting Appropriate Methodologies to Determine the Ecological Flow in Pará River Basin, in Minas Gerais State”, XVII Brazilian Symposium of Water Resources, 2007. \{In Portuguese \}. 